\title{
HYBRID ENERGY MANAGEMENT SYSTEM OF EV USING GRID TO VEHICLE SYSTEM
}

\author{
S.Kaviarasan, \\ PG Scholar [PSE], Dept. of EEE, Adhiyamaan College of Engineering, Hosur, Tamilnadu, \\ India, \\ Narayanappa, \\ Prof and Head of Dept, Dept. of EEE, Adhiyamaan College of Engineering, Hosur, \\ Tamilnadu, India
}

\begin{abstract}
To implement the Electric Vehicle-Energy Storage System (EV-ESS) to control of battery charging and discharging and control between the power generation and load. The proposed system implement a interlinking converter, which act as gateway between AC and DC sub grids in micro grid system. The converter has an able to control active and reactive power controller, which implement within the converter interlink controller. The design of reactive power controller operate depends on the RMS voltage. The PV system are used to grid tried hybrid AC/DC micro grid. For wind energy conversion using Doubly Fed Induction Generator (DFIG) used for grid tied hybrid AC/DC micro grid. The Simulation and analysis are using MATLAB SIMULINK software. The result proves the effectiveness of the proposed controller and shows the EV-ESS Charging/Discharging control and reactive power control performance efficient.
\end{abstract}

Keywords: Hybrid AC/DC microgrid, Wind turbine model, PV module, EV-ESS, Grid to Vehicle, active and reactive power control and management

Cite this Article: S.Kaviarasan and Narayanappa, Hybrid Energy Management System of Ev Using Grid to Vehicle System, International Journal of Electrical Engineering \& Technology, 10(1), 2019, pp. 30-38.

http://iaeme.com/Home/issue/IJEET?Volume=10\&Issue $=1$

\section{INTRODUCTION}

A micro grid is a localized group of electricity sources and loads that normally operate connected to and synchronous with the traditional wide area synchronous grid(macro grid), but can also disconnect to "island mode" and function autonomously as physical or economic conditions dictate. In this way, a micro grid can effectively integrate various sources of Distributed Generation (DG), especially Renewable Energy Sources (RES) - renewable electricity, and can supply emergency power, changing between island and connected modes. Control and protection are challenges to micro grids. A very important feature is also to provide multiple end-use needs as heating, cooling, and electricity at the same time since this 
allows energy carrier substitution and increased energy efficiency due to waste heat utilization for heating, domestic hot water, and cooling purposes (cross sectored energy usage).

The Department of Energy Micro grid Exchange Group defines a micro grid as a group of interconnected loads and Distributed Energy Resources (DERs) within clearly controllable entity with respect to the grid. A microgrid can connect and disconnect from the grid to enable it to operate in both connected or island-mode. The EU research project describes a microgrid as comprising Low-Voltage (LV) distribution systems with Distributed Energy Resources (DERs) (micro turbines, fuel cells, photovoltaic (PV), etc.), storage devices (batteries, flywheels) energy storage system and flexible loads. Such systems can operate either connected or disconnected from the main grid. The operation of micro sources in the network can provide benefits to the overall system performance, if managed and coordinated efficiently.

\section{METHODOLGY}

The methodology used to develop a novel reactive power controller which can eliminate these shortcomings. The reactive power controller performs two stage comparisons. In the first stage metering. Success of the V2G concept depends on power requirement. In second stage the difference is further compared with the controlled deviation of PCC RMS voltage with its corresponding reference.

The output is then fed as reactive power control input. Both EV-ESS charge/discharge controller and reactive power controller is utilized in a simulated hybrid AC/DC micro grid which is developed mimicking the real micro grid in Griffith University, Nathan campus to prove controllers' superior performance under variable loading and variable irradiation.

A hybrid AC/DC micro grid is the combination of AC and DC networks as shown in Figure. Where various $\mathrm{AC}$ and DC sources and loads are connected to the corresponding DC and $\mathrm{AC}$ networks through transformers and converters, respectively. The DC and AC networks are connected together through the bidirectional AC/DC converters which may be transformer less or with transformer. The PV conversion systems and fuel cell generators are connected to the DC network through DC/DC boosters. Light wind turbine which needs battery as energy buffer can PCC reactive power is compared with load reactive electric vehicles (EVs) and LEDs are connected to the DC network through DC/DC buck converters.

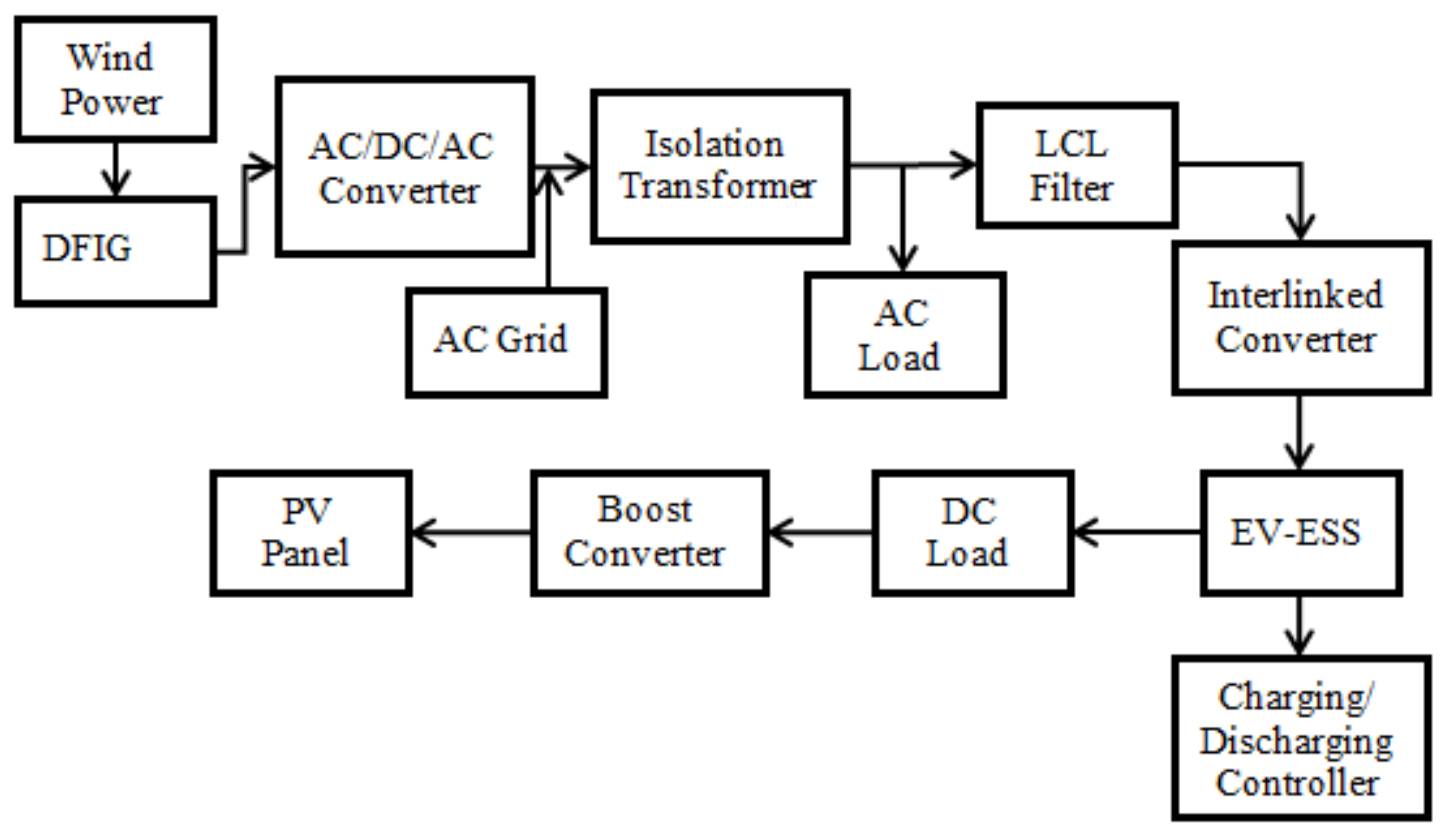


Figure 1 Block Diagram Hybrid Energy Management System of EV Using Grid To Vehicle System

Power electronics driven AC motors are connected to DC network through DC/AC converters. DC energy storages such as batteries and super capacitors are connected to the DC network through bidirectional DC/DC converters. AC power generators such as wind turbine generators and small diesel generators are connected to the AC network. AC energy storages such as flywheels are connected to AC grid through AC/AC converters. AC loads such as AC motors and heaters are connected to the AC network. The three-phase AC network of the hybrid grid can also be existing in low-voltage distribution network. Hybrid grid can be an isolated grid or connected to the utility grid through a transformer. It should be noted that a transformer may be required for the connection of some AC sources and loads if their output or input voltages are different with the AC network. The voltage level of the AC grid is 400 $\mathrm{V}$. There is still no standard voltage level for the DC network. The common voltage level currently used in most test also be connected to DC network. DC loads such as

\section{CONTROL STRATEGY}

The designed hybrid AC/DC micro grid includes two types of controller proposed as interlinking voltage source controller and EV-ESS charge/discharge controller. Overall control strategies are depicted in Figure. In this section a brief overview of the structures and strategies of these controllers are presented.

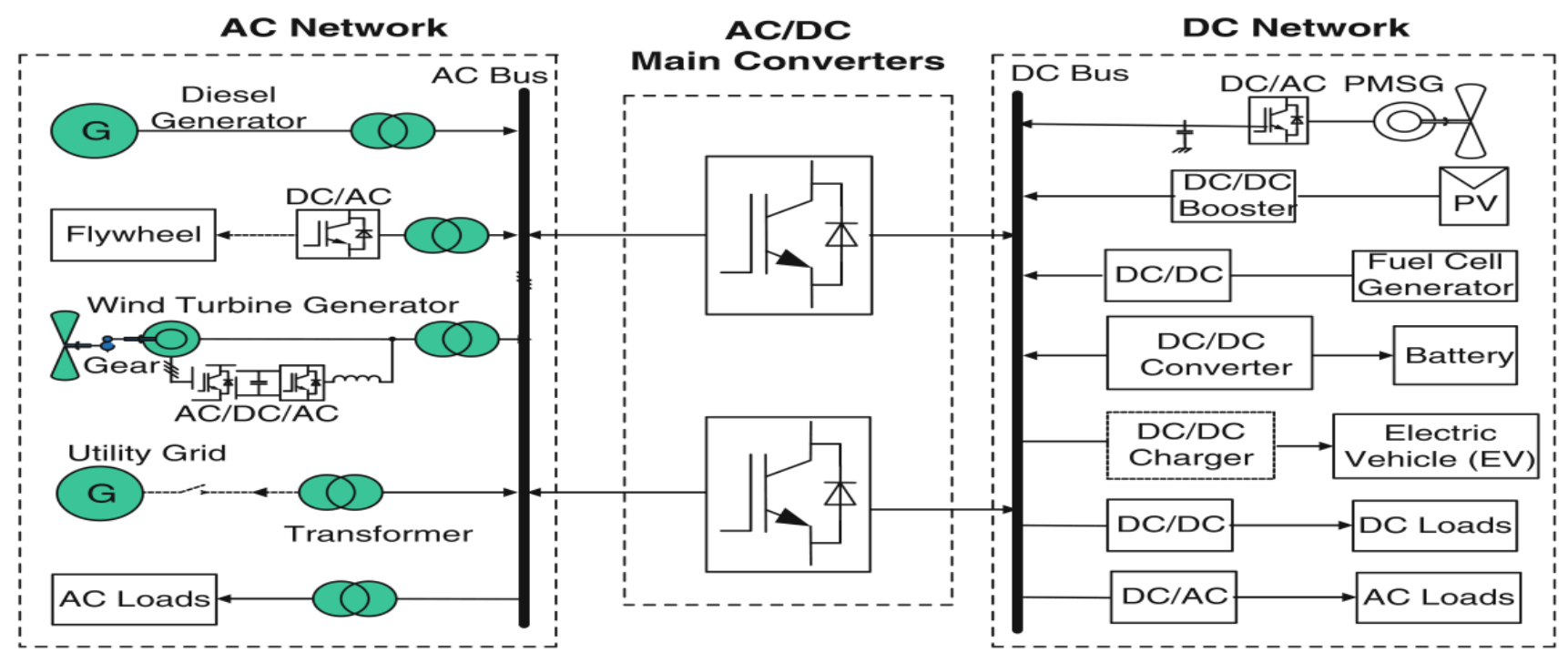

Figure 2 A typical hybrid AC/DC microgrid configuration

\subsection{Interlinking Converter Controller}

The interlinking converter consists of four interconnected subsystems.

\subsubsection{Phase Locked Loop (PLL) measurement}

Measured grid side voltage $\left(\mathrm{V}_{\mathrm{abc}}\right)$ is fed to a PLL to get instantaneous angle measurement which is later fed into abc/dq0 converter. Measured grid side voltage $\left(\mathrm{V}_{\mathrm{abc}}\right)$ and current $\left(\mathrm{I}_{\mathrm{abc}}\right)$ are passed through abc/dq0 converter to get corresponding $\mathrm{d}$ and $\mathrm{q}$ axis components i.e. $\mathrm{V}_{\mathrm{d}}$, $\mathrm{V}_{\mathrm{q}}, \mathrm{I}_{\mathrm{d}}$ and $\mathrm{I}_{\mathrm{q}}$.

\subsubsection{Bus Voltage Regulator}


The objective of this subsystem is to regulate DC bus voltage and to generate reference value for the active power control input i.e, $I_{d(r e f)}$. In order to do so measured DC voltage is compared with its reference voltage (i.e. $600 \mathrm{~V}$ ) and then passed through a proportional integral (PI) controller to generate control input $I_{d(\text { ref }) \text {. }}$.

\subsubsection{Proposed Reactive Power Controller}

Active and reactive power of a non-inertial system can be controlled by $I_{d}$ and $I_{q}$ respectively. The main task of the proposed reactive power controller is to generate reference value for $I_{q}$ which is $I_{q(r e f)}$. The controller compares PCC reactive power $(Q P C C)$ with required load reactive power $\left(Q_{\text {Load }}\right)$ and the result is passed through a PI controller. PCC RMS voltage is also compared with its reference value which in this case in $230 \mathrm{~V}_{\mathrm{rms}}$ and the result is passed through another PI controller. Both results are again compared and passed through another PI controller to generate $I_{q(r e f)}$.

\subsubsection{Current Regulator}

The main task of the current regulator is to compare $I d$ and $I q$ with their associated references $I_{d(r e f)}$ and $I_{q(r e f)}$ and decouple active and reactive power control from each other. As a result, the controller performance becomes independent of system dynamics.

\subsection{Modeling and control of photovoltaic system}

One type of DC power sources is PV panels. Individual PV conversion systems have been well studied and the related techniques have been investigated. A PV panel is simulated as a current source connected in parallel with a diode and a resistor RP and in series with resistor RS shown in below circuit.

$$
\begin{aligned}
I_{P V} & =n_{p} I_{p h}-n_{p} I_{s a t} X\left[\exp \left(\frac{q}{A k T}\left(\frac{V_{P V}}{n_{S}}+I_{P V} R_{S}\right)\right)-1\right] \\
I_{p h} & =\left(I_{S S O}+k_{i}\left(T-T_{r}\right)\right) X \frac{S}{1000}
\end{aligned}
$$

where $\mathrm{V}_{\mathrm{PV}}$ is the terminal voltage of PV panel, $\mathrm{I}_{\mathrm{ph}}$ is the photocurrent, $\mathrm{I}_{\mathrm{sat}}$ is the saturation current, $\mathrm{q}$ is the electron charge, $\mathrm{A}$ is the ideality factor, $\mathrm{k}$ is the Boltzman constant, $\mathrm{I}_{\text {sso }}$ is the short circuit current, $k_{i}$ is the short circuit current temperature coefficient, $T_{r}$ is the reference temperature, $I_{r r}$ is the reverse saturation current at $T_{r}, E_{g a p}$ is the gap energy, $n_{p}$ is the number of parallel solar cells, $\mathrm{n}_{\mathrm{s}}$ is the number of series solar cells, $\mathrm{S}$ is the solar irradiation level and $\mathrm{T}$ is the junction temperature. The output power of a PV panel depends on I-V curve as shown below. Where $I_{s c}$ and $V_{o c}$ are the short circuit current and open-circuit voltage, respectively. 


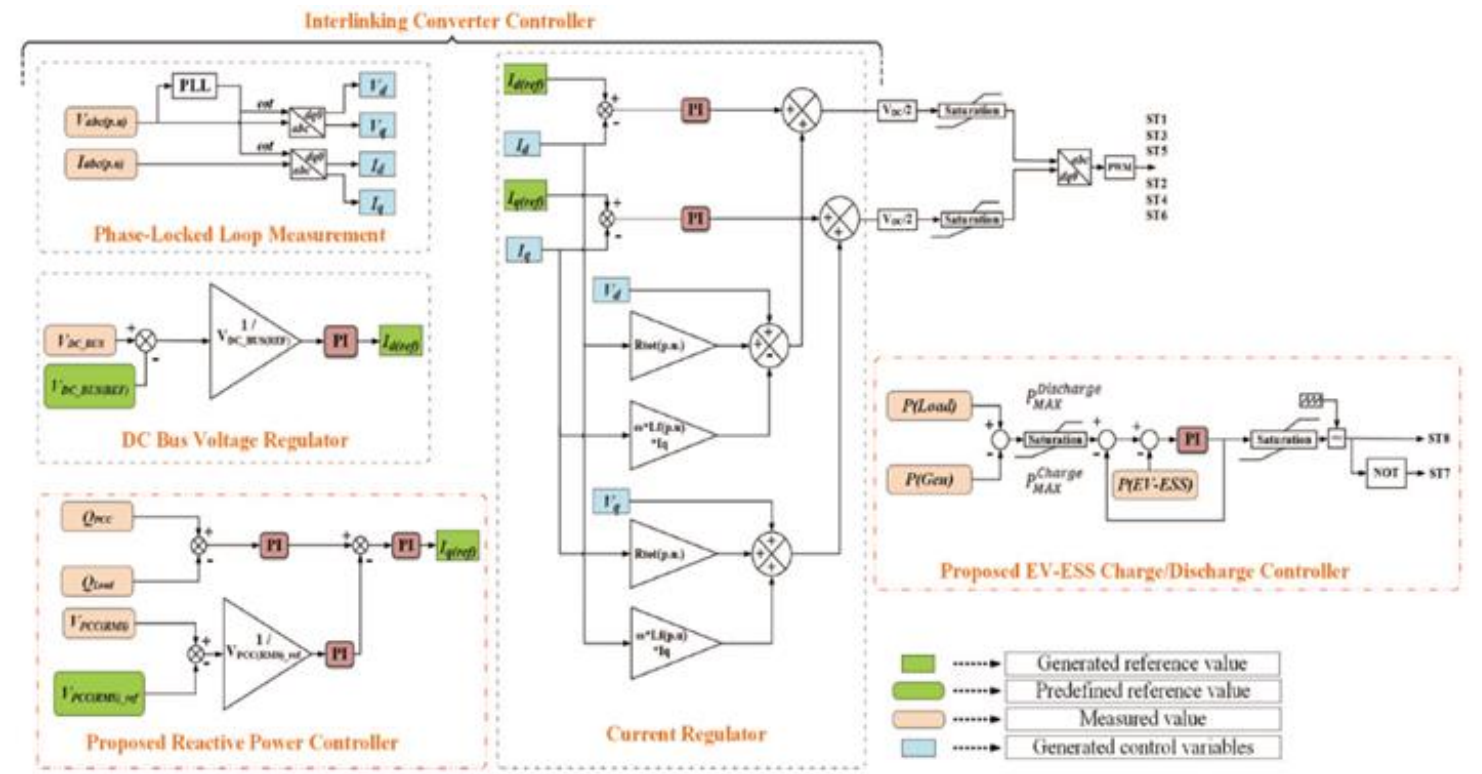

Figure 3 Overall control strategies

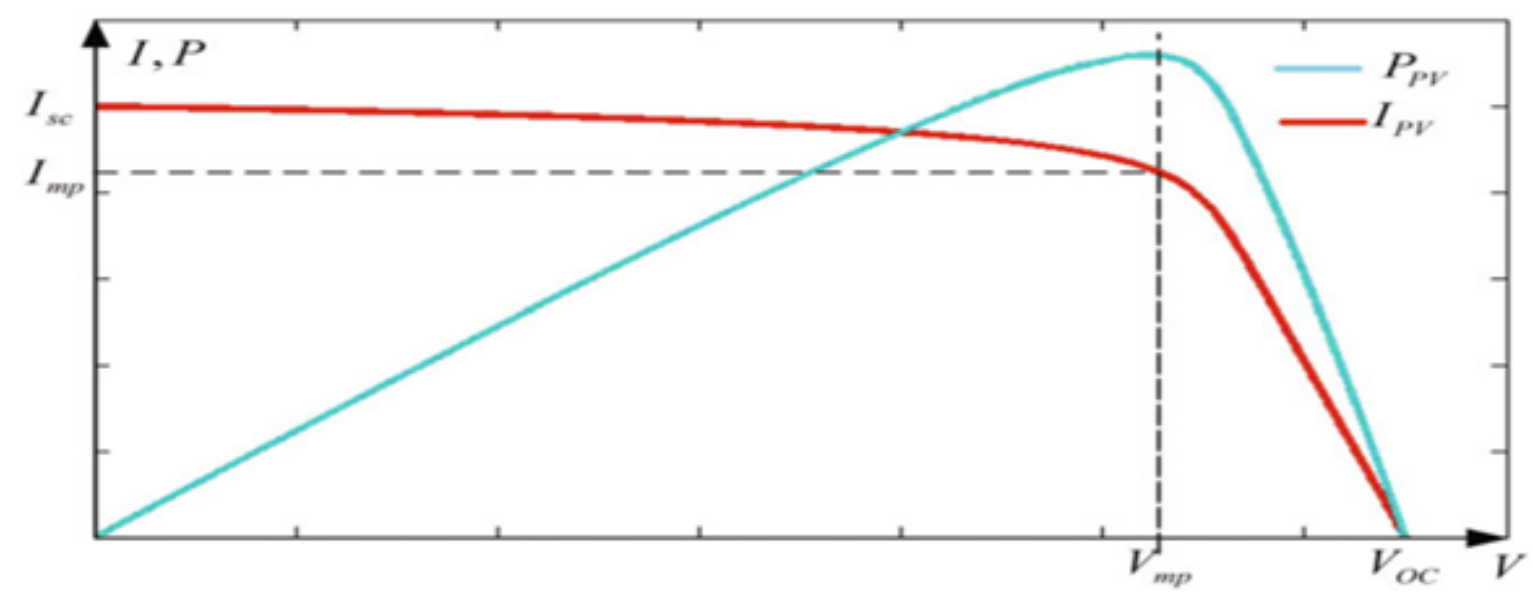

Figure 4 Output power of a PV panel depends on I-V curve

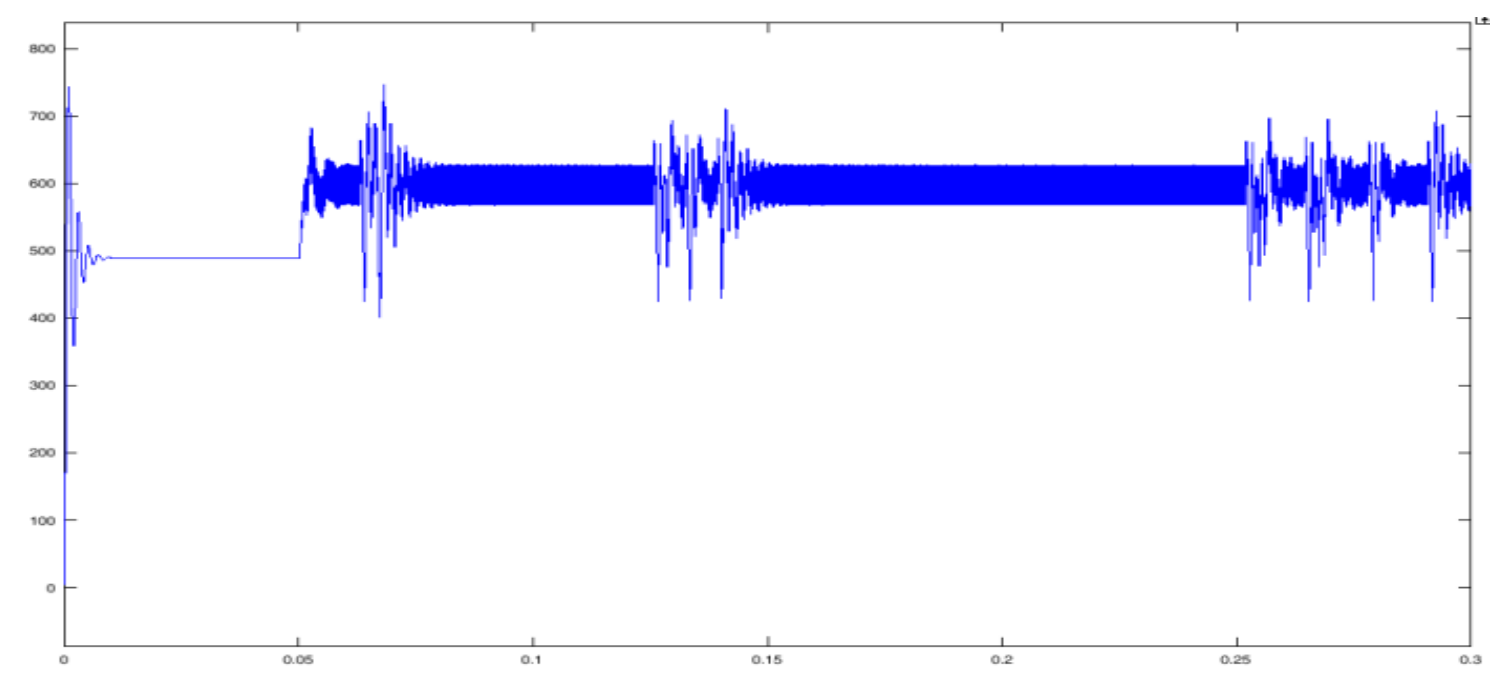

Figure 5 Output for Solar Panel Voltage

\section{SIMULATION RESULT}


Hybrid Energy Management System of Ev using Grid to Vehicle System
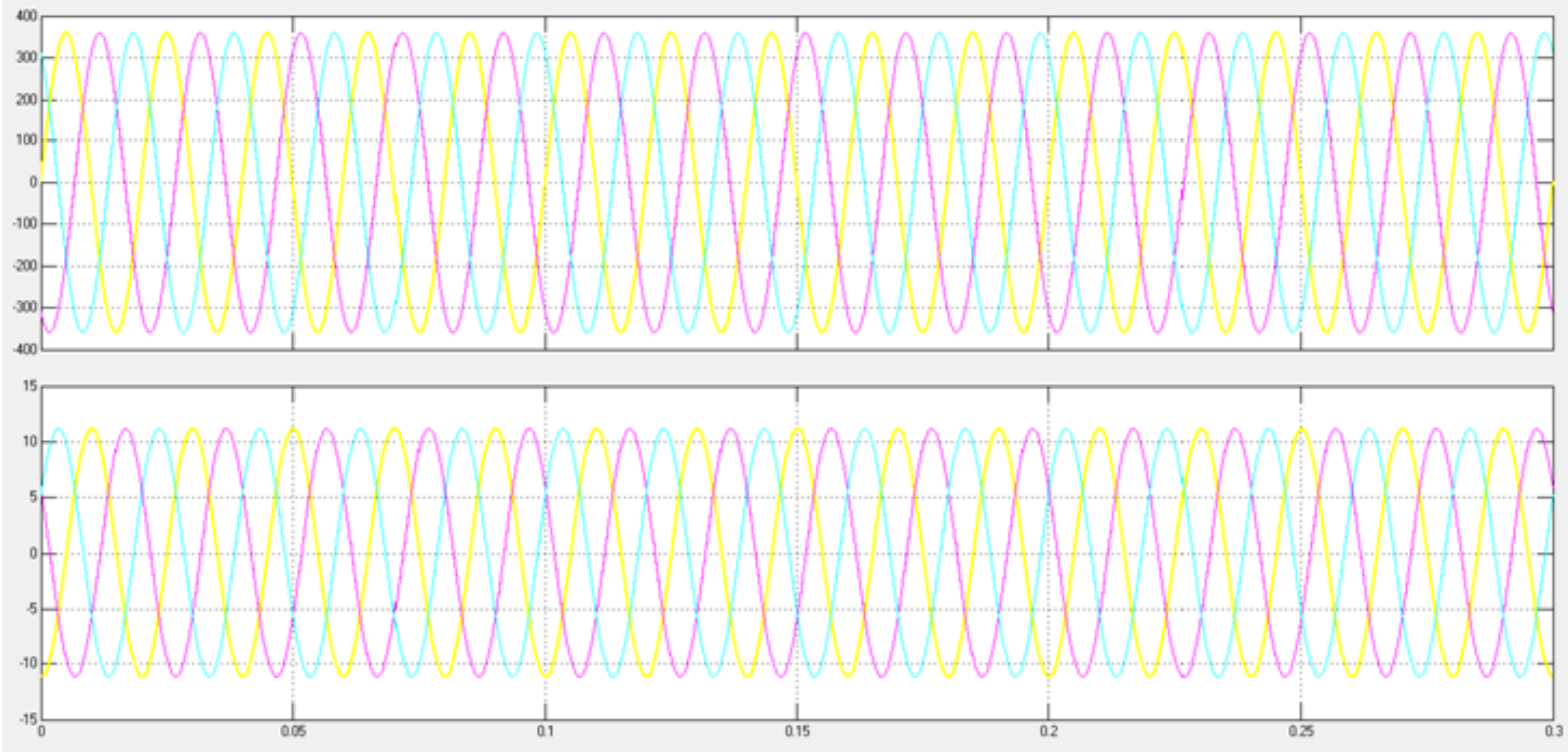

Figur 6 Grid Voltage and Current
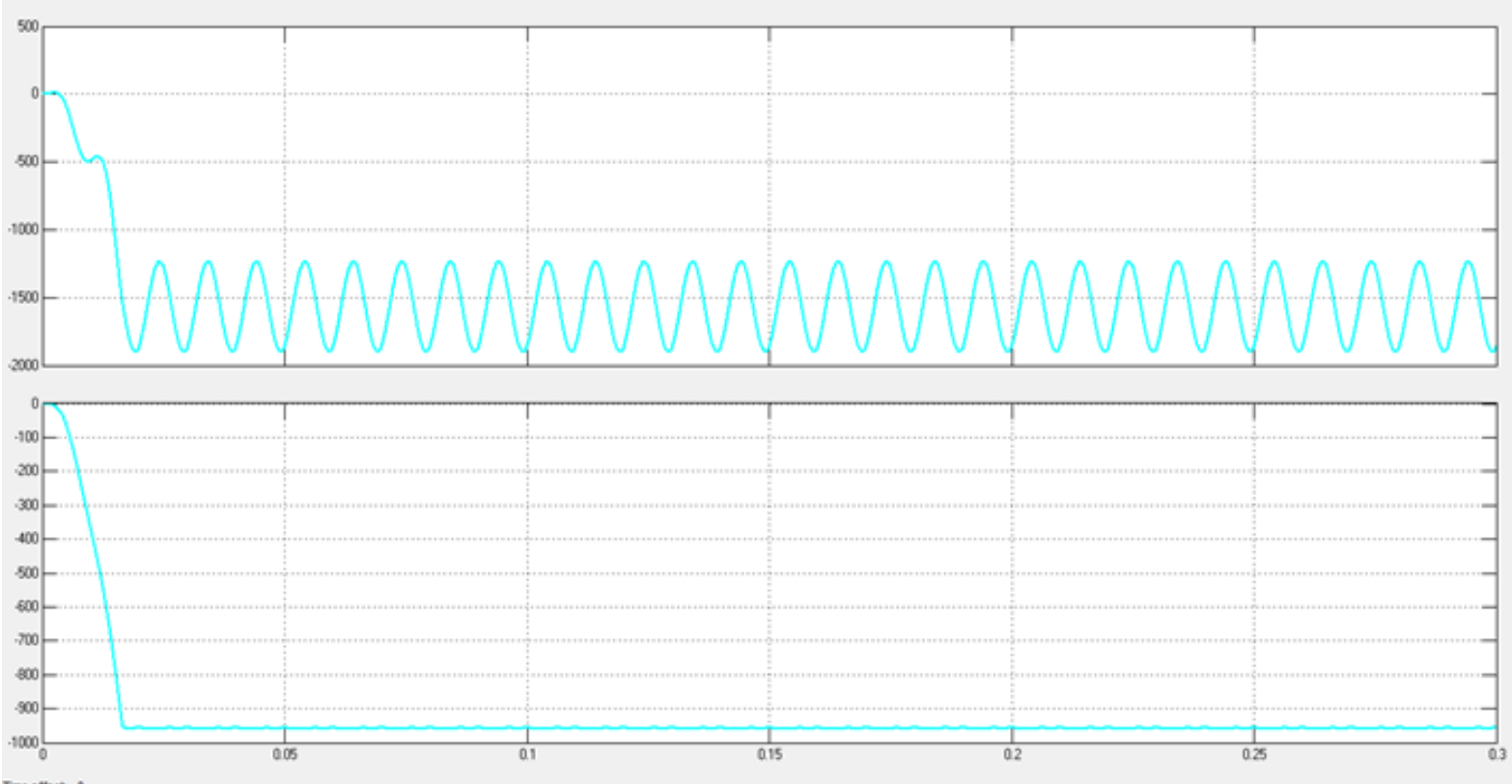

Figure 7 Active and Reactive Power 
S.Kaviarasan and Narayanappa

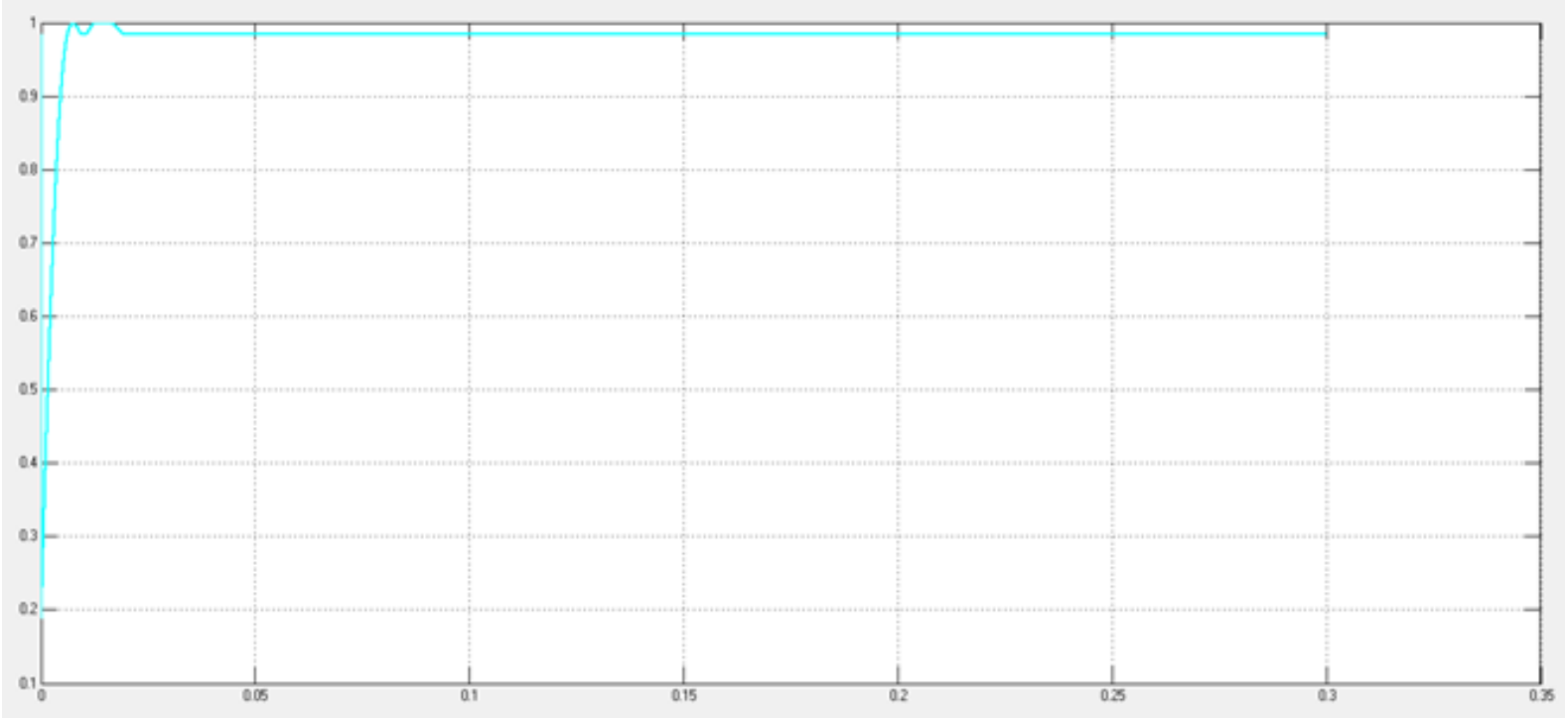

Figure 8 Power Factor

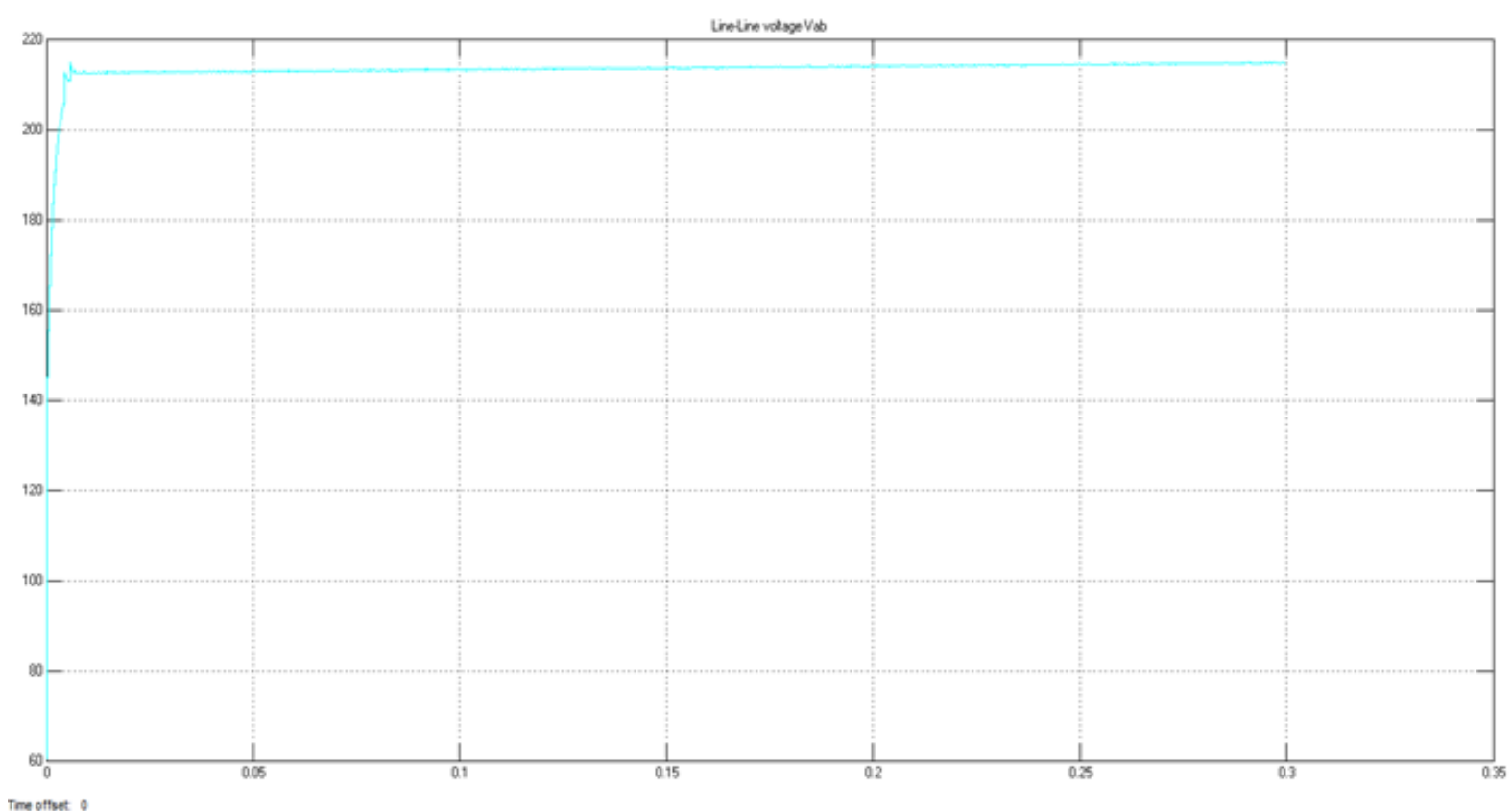

Figure 9 Bidirectional Converter Voltage 


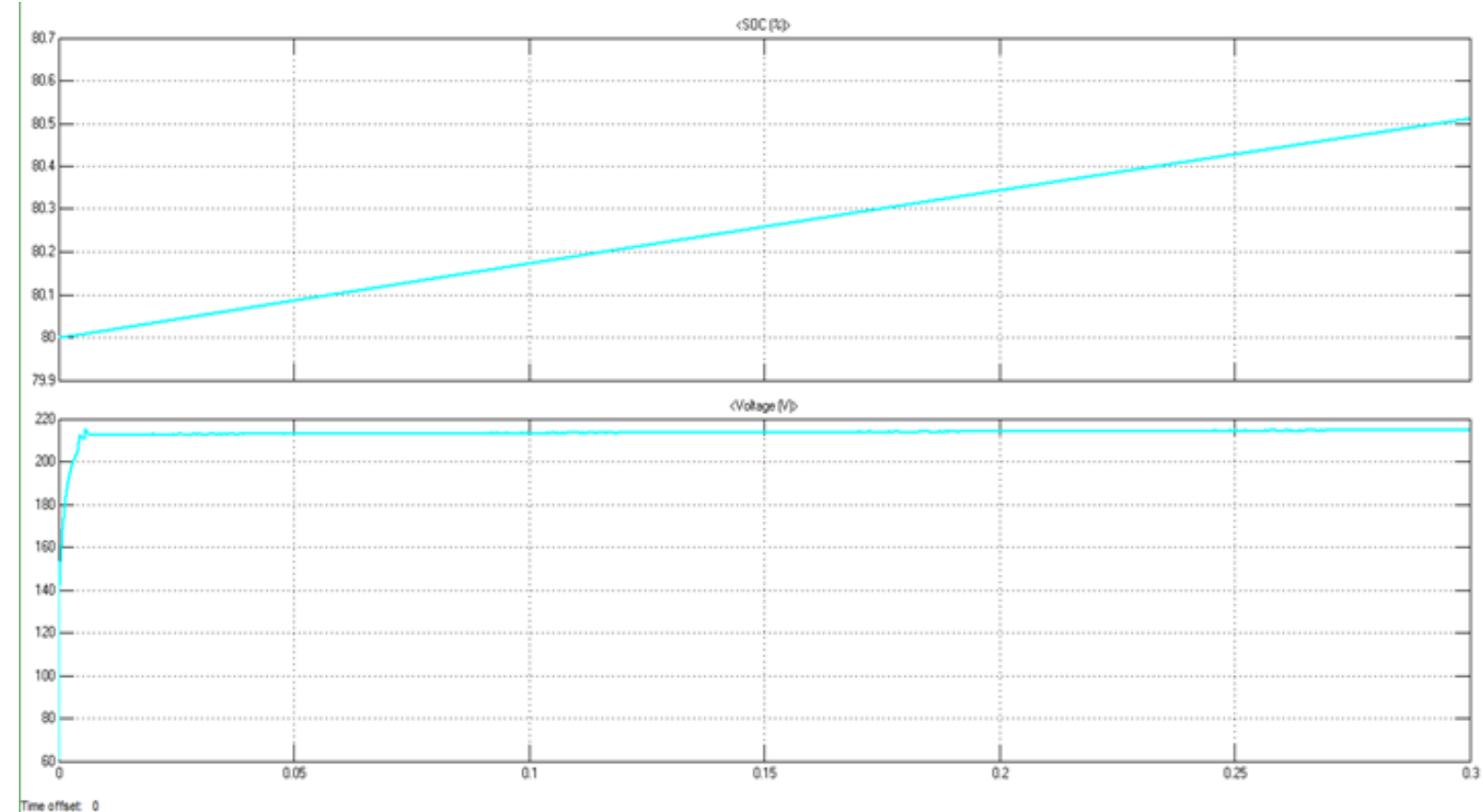

Figure 10 Battery Charging Mode

\section{CONCLUSION}

An EV-ESS charge/discharge controller has been proposed and designed to manage power flow between the AC and DC sub grids of a hybrid AC/DC microgrid. Additionally, an interlinking controller is designed to stabilize voltages of corresponding buses and to maintain overall control of the system. Simulation results show that both reactive power controller and EV-ESS charge/discharge controller efficiently manage reactive and active power respectively within the designed system. The effects of wind gust on DFIG WT, uncertainty of PHEV charging pattern and multiple pair of DC and AC buses have not been considered in this paper, which can be identified as future scopes of this research.

\section{REFERENCE}

[1] Liu X., Wang P., and Loh P. C., "A hybrid ac/dc microgrid and its coordination control," IEEE Transactions on Smart Grid, vol. 2, no. 2, pp. 278-286, Jun. 2011, ISSN: 19493053.

[2] Loh P. C., Li D., Chai Y. K., and F. Blaabjerg, "Autonomous control of interlinking converter with energy storage in hybrid ac x2013;dc microgrid," IEEE Transactions on Industry Applications, vol. 49, no. 3, pp. 1374-1382, May 2013, ISSN: 0093-9994.

[3] Narayanappa , Thanushkodi, K., "Photovoltaic Based Power Quality Improvement", U.P.B. Sci. Bull., Series C, Vol. 74, Iss. 2, 2012, ISSN 1454-234x.

[4] Narayanappa, N. , Thanushkodi, K., "Photovoltaic unified power quality conditioner sag and interruption mitigation", Australian Journal of Electrical \&Electronics Engineering, Vol. 9, No. 2, 2012, pp. 145-152, ISSN: 1448-837X.

[5] Jian L., Xue H., Xu G., Zhu X., Zhao D., and Shao Z. Y., "Regulated Charging of Plug-in Hybrid Electric Vehicles for Minimizing Load Variance in Household Smart Microgrid," IEEE Transactions on Industrial Electronics, vol. 60, no. 8, pp. 3218-3226, Aug. 2013, ISSN: 0278-0046. 
[6] Bhagiya R. D., Dr. Patel R. M., "Power Management And Control For Hybrid Pv/Battery Dc Microgrid", International Journal of Electrical Engineering \& Technology (IJEET) Volume 9, Issue 5, September-October 2018, pp. 33-41, ISSN Online: 0976-6553.

[7] Katiraei F. and Iravani M., "Power management strategies for a microgrid with multiple distributed generation units," IEEE Transactions on Power Systems, vol. 21, no. 4, pp. 1821-1831, Nov. 2006, ISSN: 0885-8950.

[8] Guerrero J. M., Poh Chiang L., Tzung-Lin L., and Chandorkar M., "Advanced Control Architectures for Intelligent Microgrids - Part II: Power Quality, Energy Storage, and AC/DC Microgrids," IEEE Transactions on Industrial Electronics, vol. 60, no. 4, pp. 1263-1270, 2013, ISSN: 0278-0046.

[9] Surekha S Bhalshankar, Thorat C. S., "Hybrid Renewable Energy Ac Based Nano-Grid Distributed Generation System For Smart Home", International Journal of Electrical Engineering \& Technology (IJEET) Volume 9, Issue 3, May- June 2018, pp. 43-49, ISSN Online: 0976-6553.

[10] Schauder C. and Mehta H., "Vector analysis and control of advanced staticvar Mitsubishi Motors Australia. [Online]. Available: compensators," Generation, Transmission and Distribution, IEE Proceedings C, vol. 140, no. 4, pp. 299-306, Jul. 1993, ISSN: 01437046. 